\title{
Study on Technological Parameters of Pilot Production of Ethanol
}

\author{
Zhengheng Huang, Yingjun Xie, Fang Yin*, Wudi Zhang, Jing Liu \\ College of Energy and Environment Science, Yunnan Normal University, Kunming, China
}

Email address:

769602295@qq.com (Zhengheng Huang),yf6709@sina.com (Fang Yin)

${ }^{*}$ Corresponding author

To cite this article:

Zhengheng Huang, Yingjun Xie, Fang Yin, Wudi Zhang, Jing Liu. Study on Technological Parameters of Pilot Production of Ethanol. American Journal of Energy Engineering. Vol. 7, No. 1, 2019, pp. 39-44. doi: 10.11648/j.ajee.20190701.15

Received: April 27, 2019; Accepted: June 3, 2019; Published: June 15, 2019

\begin{abstract}
Cassava and corn are the two main ingredients in the process of producing fuel ethanol. This paper is mainly based on experiments. In this experiment, the traditional ethanol fermentation with cassava and corn as raw materials was compared with the the industrial ethanol fermentation with the same raw material, and the technological parameters of ethanol fermentation in traditional ethanol fermentation and industrial ethanol fermentation were compared and studied. The traditional double enzyme method was used for ethanol fermentation. Liquefaction temperature ( 70 plus or minus 1$)^{\circ} \mathrm{C}$, Saccharification temperature $(60 \text { plus or minus } 1)^{\circ} \mathrm{C}$, Fermentation temperature $(30 \text { plus or minus } 1)^{\circ} \mathrm{C}$. Experimental results show that: The average alcoholic production rate of corn was $36.64 \%$ and the average alcoholic production rate of cassava was $42.46 \%$ in the traditional ethanol fermentation, the average alcoholic production rate of corn was $38.22 \%$ and the average alcoholic production rate of cassava was $44.76 \%$ in the industrial ethanol fermentation. The industrial ethanol fermentation experiment is better than the traditional ethanol fermentation by comparison, because the former has better sealed anaerobic environment and greater capacity. It is suitable for large-scale production parameter study, in order to obtain higher utilization rate of raw materials, it shows a higher rate of alcohol production.
\end{abstract}

Keywords: Ethanol, Traditional Small Scale Ethanol Fermentation, Industrial Experiment Research, Yield of Liquor

\section{Introduction}

Nowadays, countries all over the world are carrying out continuous research on the utilization of renewable energy. Biomass energy, one of the renewable energy sources, is favored for its advantages of recycling and cleaning. Among them, biomass liquid fuel is a new energy source which all countries are developing vigorously [1]. The heavy use of coal, oil and natural gas not only causes environmental pollution, it also consumes a lot of primary energy, finding an alternative source of clean energy is especially important. Ethanol is produced by fermentation of biomass, after dehydration, purification and denaturation, fuel ethanol can be added into gasoline as an additive.

Fully burning gasoline can also greatly reduce the emission of air pollutants. According to present situation, the two synthetic methods widely used in ethanol production in the world include ethylene water synthetic and biological fermentation. Due to the problems of crude oil resources and the rise of ethylene prices in recent years, ethylene hydration was replaced by biological fermentation [2]. Most bioethanol is produced by enzymatic desaccharification and fermentation of agricultural products or agricultural and forest wastes such as sugarcane, corn, potato and plant straw [3]. The basic principle of microorganism fermentation to produce ethanol based on corn and cassava is to use the abundant starch contained in corn and cassava, the liquefied enzyme and saccharification enzyme play an important role in traditional double enzymes fermentation methods, the starch is decomposed and converted into fermentable sugars that can be used by yeast, then add yeast. It's metabolized by yeast. The yeast is under anaerobic conditions, microbes convert glucose into pyruvate through the glycolysis process (also known as the EM pathway), pyruvate decarboxylated further to form acetaldehyde, the process by which acetaldehyde is eventually reduced to ethanol. The main microorganism used in ethanol production in industry is yeast, some other bacteria, for 
example, Zymomonas Mobilis can also carry out ethanol fermentation [4-6].

Yeast belongs to facultative anaerobic bacteria. In the process of fermentation of ethanol, yeasts first undergo aerobic propagation, then it goes into anaerobic breathing, anaerobic metabolic fermentation was performed, a series of biochemical reactions occur in this process [7]. In terms of production technology, fermented mash liquid obtained from simple pretreatment of raw materials, starch and dextrin contained in fermented mash liquid are saccharized by saccharifying enzyme. It is used to hydrolyze starch into sugars, and protein in fermented mash liquid is under the action of protease, the hydrolysis reaction including peptone, peptides and various amino acids, they all exist as small molecules, these hydrolytic products, some are absorbed by yeast cells to form thalli, the other part of the fermentation produces alcohol and carbon dioxide, it also can produce the by-product alcohol oil, glycerol and so on [8-10].

Nowadays, From the overall level of ethanol production in China, there is still a big gap between China and other advanced countries in terms of equipment for large-scale ethanol production and key production and fermentation technologies. Although the research and development applied foreign corresponding production procedures. there is a gap in production technology, it caused a series of problems such as high energy consumption, high cost and high probability of fermentation failure [11]. Therefore, the relevant technologies in China need to be improved. Furthermore, industrial development also faces many problems in domestic, such as the development of non-grain raw materials, research on new production technology, development of new production equipment [12]. Although our country's production equipment is far from a few developed countries complete and advanced so far, but there had one thing is certain, with the continuous progress of domestic science and technology, the scale of ethanol production will prosperity.

\section{Traditional Experiment Small Ethanol Fermentation}

\subsection{Materials and Experimental Instruments}

\subsubsection{Materials}

Raw material: SF-130 stainless steel high-speed universal crusher production line is adopted to screen corn and cassava powder, crushing fineness through 10-120 mesh, the mixture is crushed and sifted again [13].
Enzyme material: The food additive medium temperature $\alpha$ - amylase: the optimum temperature is $60^{\circ} \mathrm{C}$ to $70^{\circ} \mathrm{C}$, the $\mathrm{pH}$ range is 5.2-6.2. Medium temperature saccharifying enzyme: the optimum temperature is $58^{\circ} \mathrm{C}-60^{\circ} \mathrm{C}$ [14], the $\mathrm{pH}$ range is 5.2-6.2.

\subsubsection{Experimental Instruments}

Stainless steel sink, 10L glass fermentation tank, FA224 electronic balance, $\mathrm{pH}$ meter, saccharimeter, shaker, ZX-WK3 high precision temperature controller, the heating rods used for heating, etc.

\subsection{Experimental Operation}

\subsubsection{Soak Raw Material}

Weigh $2 \mathrm{~kg}$ of raw material to $10 \mathrm{~L}$ glass fermentation tank according to $30 \%$ dry matter concentration, add water which is four times the volume of the raw material. The total system is 10 kilograms. Mix well and let stand for 6 to 7 hours, the starch molecules of the raw materials are fully absorbed and expanded, it is good for gelatinization, liquefaction and saccharification.

\subsubsection{Activation of Yeast}

According to $0.05 \%$ of the raw material, angle wine's highly active dry yeast was taken into the conical bottle, then add some distilled water, $160 \mathrm{r} / \mathrm{min}$ in the shaker, 35 degrees Celsius for 30 minutes.

\subsubsection{Mixing Materials and Liquefying}

Place the fermentation tank in the sink, use the heating rod to heat up the water bath and cook until it is gelatinized, cooled to below $70{ }^{\circ} \mathrm{C}$. Subsequently, the medium temperature $\alpha$ - amylase was added according to $0.01-0.02 \%$ of the raw material, stir in water bath to liquefy for 15 minutes.

\subsubsection{Mixing Materials and Saccharifying}

When the liquefaction is complete, up to $90{ }^{\circ} \mathrm{C}$, stir for 30 minutes, and then stop heating, cool the tank to 60 degrees Celsius, medium - temperature saccharification enzyme was added as raw material $0.01-0.02 \%$, stir in the water bath and saccharify for 15 minutes.

\subsubsection{Fermentation}

After saccharification, cooling to below 40 degrees Celsius rapidly, add yeast activator, enable ZX-WK3 high precision temperature controller, let stand for constant temperature $30^{\circ} \mathrm{C}$ fermentation for 120 hours.

\subsection{Experimental Data Recording}

Table 1. Process parameters of corn ethanol production by traditional experiment.

\begin{tabular}{|c|c|c|c|c|c|c|c|}
\hline Groups & $\begin{array}{l}\text { raw material } \\
(\mathrm{g})\end{array}$ & $\begin{array}{l}\text { liquifying } \\
\text { enzyme (g) }\end{array}$ & $\begin{array}{l}\text { Saccharif-ying } \\
\text { enzyme (g) }\end{array}$ & Yeast (g) & $\begin{array}{l}\text { Degree of } \\
\text { sugar }\end{array}$ & $\begin{array}{l}\text { degree of liquor } \\
\text { before fermenta-tion }\end{array}$ & $\begin{array}{l}\text { liquor yield after } \\
\text { fermenta-tion (\%) }\end{array}$ \\
\hline 1 & 2143.24 & 4.05 & 4.36 & 11.10 & 6 & - & 37.58 \\
\hline 2 & 2206.39 & 4.10 & 4.41 & 10.85 & 5 & - & 33.79 \\
\hline 3 & 2173.91 & 4.11 & 4.17 & 12.74 & 7 & 1 & 40.36 \\
\hline 4 & 2232.37 & 4.23 & 4.03 & 11.87 & 5 & - & 34.81 \\
\hline average & 2188.98 & 4.12 & 4.24 & 11.64 & 5.75 & 0.25 & 36.64 \\
\hline
\end{tabular}


Table 2. Process parameters of cassava ethanol production by traditional experiment.

\begin{tabular}{llllllll}
\hline Groups & $\begin{array}{l}\text { raw material } \\
\text { (g) }\end{array}$ & $\begin{array}{l}\text { liquifying } \\
\text { enzyme } \mathbf{( g )}\end{array}$ & $\begin{array}{l}\text { Saccharif-ying } \\
\text { enzyme (g) }\end{array}$ & Yeast (g) & $\begin{array}{l}\text { Degree of } \\
\text { sugar }\end{array}$ & $\begin{array}{l}\text { degree of liquor } \\
\text { before fermenta-tion }\end{array}$ & $\begin{array}{l}\text { liquor yield } \\
\text { after fermenta-tion (\%) }\end{array}$ \\
\hline 1 & 2412.51 & 4.31 & 4.43 & 12.84 & 8 & 1 & 42.01 \\
2 & 2063.15 & 4.13 & 4.08 & 13.12 & 11 & 1 & 45.97 \\
3 & 2269.84 & 4.29 & 4.29 & 12.88 & 12 & 2 & 41.10 \\
4 & 2112.53 & 4.21 & 4.17 & 11.96 & 10 & 2 & 40.76 \\
average & 2214.51 & 4.24 & 4.24 & 12.70 & 10.25 & 1.50 & 42.46 \\
\hline
\end{tabular}

\section{The Pilot-scale Equipment Ethanol Production}

\subsection{Materials and Experiment Equipment}

\subsubsection{Materials}

The same experimental materials were used for small ethanol fermentation in the traditional laboratory, enable
SF-130 stainless steel high-speed universal crusher production line is adopted to screen corn and cassava powder, crushing fineness through 10-120 mesh, the mixture is crushed and sifted again.

\subsubsection{Experimental Facilities}

The complete set of equipment for pilot anaerobic reaction is adopted.

(I) Equipment technical parameters.

Table 3. Technical parameters of pilot process.

\begin{tabular}{|c|c|c|c|c|c|}
\hline Item & Mixing tank & liquefied tank & Saccharify-ing tank & fermentation tank & vaporized tank \\
\hline Volume (L) & 60 & 60 & 50 & 50 & 50 \\
\hline Heating area (M2) & 0.45 & 0.8 & 0.38 & 0.38 & 0.38 \\
\hline vacuum degree (MPa) & -0.06 & & & & \\
\hline Power of stirring $(\mathrm{KW})$ & 0.55 & 0.55 & 0.37 & 0.55 & 0.37 \\
\hline Revolving speed (r/min) & 20 & 36 & 65 & 65 & 36 \\
\hline
\end{tabular}

(II) Introduction to main equipment structure.

1. Mixing tank and liquefied tank.

The mixing tank and the liquefied tank are composed of the tank cover, the tank body, the agitator paddle, the flushing port the breathing port, the feeding port, the discharge valve and the glass observation port. The tank body is polished internally, and the flushing port is connected to the tap water pipe. The breathing port is equipped with manual valve, which does not contact with the bottom, the tank is equipped with a mixing device, and the top is equipped with a speed reducer to drive the stirring paddle, which can be mounted, dismantled and cleaned. The bottom of the tank is equipped with the upper tensioning manual valve, which can meet no dead angle in the tank, convenient for discharging and cleaning. The temperature meter is set at $1 / 2$ of the tank body, and the temperature sensor is connected to it to display the temperature. The upper part of each tank is equipped with a pressure reading meter to accurately display the pressure value inside the tank.

\section{Saccharifying tank.}

The structure of saccharifying tank is the same as that of mixing tank and liquefaction tank. However, the liquid tank has an additional pressure limit automatic spring valve compared with the mixing tank, when it is start to sterilize ensure the safety control in high temperature and high pressure.

3. Fermentation tank.

The structure of fermentation tank is the same as that of mixing tank and liquefaction tank. However, its breathing port is different from the mixing tank and the liquid tank, its breathing port extends directly to the bottom of the tank and comes into direct contact with the material and liquid in the tank.

4. Vaporized tank and fractionating tower.

The structure of evaporation tank is the same as that of mixing tank and liquefaction tank. However, the evaporator has no breathing port and is connected to the fractionating tower by one more through pipe, it used to heat the mixture of ethanol and water in gaseous state after heating up to the fractionator.

The JH-150 distillation column was used, recovery capacity: $5-10 \mathrm{~kg} / \mathrm{h}$, Processing capacity: $10-20 \mathrm{~kg} / \mathrm{h}$, concentration: $90-95 \%$. The bottom of the column consists of a cylindrical double tower body, a thermometer and a fractionation temperature control knob. The hollow part of the double tower is connected with a mixture of ethanol and water volatilized from the evaporating tank, tap water is available in the interlayer, and the thermometer shows the top fractionation temperature, the fractionation temperature control knob controls the fractionation temperature by regulating the flow of water through the interlayer.

\subsection{Design of Experiment}

\subsubsection{Preparation Before Starting}

1. Clean all parts in contact with materials.

2. Check all water valves, oil valves and circuit switches carefully.

3. Check that all sturdy bolts are loose and that all valves are flexible and in the necessary opening and closing state. 


\subsubsection{Mixture Stage}

The raw materials that have been crushed and sifted are mixed into the mixing tank at a ratio of 1: 4 water to water ratio of the material, and the mixture is heated to 60 degrees Celsius at the same time.

\subsubsection{Liquefaction Stage}

Transfer the material that has been grouted to the liquefaction tank through the vacuum pump. At the same time, it will rapidly heat up to 95 degrees Celsius and keep warm for 1 hour, keep stirring continuously, and try not to stick the material to the wall of the tank. After liquefaction, it will naturally cool down to 50-60 degrees centigrade, and then add saccharifying enzyme, keep the saccharification for 30 minutes and measure the saccharification degree [15].

\subsection{Process Parameters}

Table 4. Process parameters of corn ethanol production by pilot production.

\begin{tabular}{|c|c|c|c|c|c|c|c|}
\hline Groups & $\begin{array}{l}\text { raw material } \\
(\mathrm{g})\end{array}$ & $\begin{array}{l}\text { liquifying } \\
\text { enzyme (g) }\end{array}$ & $\begin{array}{l}\text { Saccharif-ying } \\
\text { enzyme (g) }\end{array}$ & Yeast (g) & $\begin{array}{l}\text { Degree of } \\
\text { sugar }\end{array}$ & $\begin{array}{l}\text { Liquor of precision } \\
\text { before fermentation }\end{array}$ & $\begin{array}{l}\text { liquor yield } \\
(\%)\end{array}$ \\
\hline 1 & 8776.90 & 17.14 & 16.63 & 44.42 & 9 & 1 & 38.61 \\
\hline 2 & 4501.65 & 8.68 & 8.43 & 26.83 & 8 & - & 37.83 \\
\hline
\end{tabular}

Table 5. Process parameters of cassava ethanol production by pilot production.

\begin{tabular}{|c|c|c|c|c|c|c|c|}
\hline Groups & $\begin{array}{l}\text { raw material } \\
(\mathrm{g})\end{array}$ & $\begin{array}{l}\text { liquifying } \\
\text { enzyme (g) }\end{array}$ & $\begin{array}{l}\text { Saccharifying } \\
\text { enzyme (g) }\end{array}$ & Yeast (g) & Degree of sugar & $\begin{array}{l}\text { Liquor of precision } \\
\text { before fermentation }\end{array}$ & $\begin{array}{l}\text { liquor yield } \\
(\%)\end{array}$ \\
\hline 1 & 8836.24 & 16.77 & 18.07 & 47.11 & 14 & 2 & 40.56 \\
\hline 2 & 4375.14 & 8.34 & 8.81 & 18.04 & 13 & 2 & 48.96 \\
\hline
\end{tabular}

\section{Results and Discussion}

According to the experiment measured data:

Table 6. Comparison process of ethanol production between corn and cassava

\begin{tabular}{llll}
\hline & Parameter & traditional experiment & pilot production \\
\hline \multirow{4}{*}{ corn } & Sugar degree & 5.75 & 8.5 \\
& Liquor degree & 0.25 & 0.5 \\
& Liquor yield & 36.64 & 38.22 \\
\multirow{4}{*}{ cassava } & Sugar degree & 8.75 & 13.5 \\
& Liquor degree & 1.5 & 2 \\
& Liquor yield & 42.46 & 44.76 \\
\hline
\end{tabular}

We can get the information from table 6:

The average saccharinity of traditional ethanol fermentation with corn as raw material was 5.75 and the yield of liquor was $36.64 \%$, the average saccharinity of traditional ethanol fermentation with cassava as raw material was 8.75 and the liquor yield was $42.46 \%$, the average saccharinity of ethanol produced by industrial experiment with corn as raw material was 8.50 and the liquor yield was $38.22 \%$, the average saccharinity of ethanol produced by industrial experiment with cassava as raw material was 15 and the liquor yield was $44.76 \%$.

\subsection{Comparison of Sugar Values}

Saccharinity is the concentration unit of solids in the sugar solution, which is an important parameter to reflect the degree used different ways.

\subsubsection{Sterilization Stage}

Heat up the material from the previous process to 121 degrees Celsius, stir for 30 minutes, then enter the condenser plate to cool down to 30 degrees Celsius and transfer it to the fermentation tank.

\subsubsection{Fermentation Stage}

In the fermentation tank, keep stirring continuously, and set a constant temperature of 30 to ferment for 120 hours. After the fermentation, the next process is carried out.

\subsubsection{Distillation Stage}

The fermented liquid is pumped into the distilling evaporator to be heated and evaporated, keeping the temperature between 110 and 118 degrees Celsius. The concentration of the finished product is controlled by fractionation temperature. of saccharification in the production and fermentation of ethanol.

1. Horizontal comparison of different materials, the average saccharification degree of corn after saccharification was 5.75 and that of cassava after saccharification was 8.75 in the traditional ethanol fermentation, the average saccharification degree of corn after saccharification was 8.50 and that of cassava after saccharification was 15 in the industrial ethanol fermentation. it is observed that, the average sugar of corn was lower than that of cassava in both the traditional ethanol fermentation and the industrial ethanol fermentation, indicating that the degree of saccharification of corn was lower in the process.

2. Vertical comparison with different scale experiment, the average saccharinity of the traditional experiment corn was 5.75, that of the industrial experiment corn was 8.5, and the saccharinity of the experimental corn increased by 47.83 percent year on year. The average sugar of cassava was 10.25 in the traditional experiment, the average sugar of cassava was 13.50 in the industrial experiment, the sugar content increased by 31.71 percent year on year. The results indicate that the medium - test raw materials have good liquefaction and saccharification, which may be related to the fermentation device. In small fermentation, the $10 \mathrm{~L}$ glass tank water bath was used to stir the saccharification by 
hand. The uneven stirring led to the uneven saccharification and limited degree of saccharification.

\subsection{Comparison of Liquor Yield Values}

1. Horizontal comparison of different materials. The average liquor yield of corn was $36.64 \%$ and that of cassava was $42.46 \%$ in the traditional experiment, the cassava was $5.82 \%$ higher than corn by comparison. The average yield of corn was $38.22 \%$ and that of cassava was $44.76 \%$ in the industrial experiment, the cassava is 6.54 percent higher than corn by comparison. It can be seen that cassava produces more ethanol than corn. Analysis of the reasons, the characteristics of cassava starch has the following several aspects: high amylopectin content, the degree of polymerization of molecules, cassava starch and fiber adhesion strong, gelatinization temperature in $51 \sim 65{ }^{\circ} \mathrm{C}$, the gelatinization transparency is good, the mucus is long, the paste has high heat sticking degree but weak coagulability, and the starch has less non-starch impurities (such as ash, protein and grease) [16]. According to the fermentation principle of bioethanol production, higher liquor yield has more fermentable sugar, so cassava starch content is higher, and the starch in it is easier to be liquefied and saccharified, so it is easier to be metabolized and used by yeast.

2. Vertical comparison with different scale experiment. The average liquor yield of corn was $36.64 \%$ in the traditional ethanol fermentation and $38.22 \%$ in the industrial ethanol fermentation, it was up 4.31 per cent year on year. The average liquor yield of cassava was $42.46 \%$ in the traditional ethanol fermentation and $44.76 \%$ in the industrial ethanol fermentation, it was up 5.42 percent year on year. The industrial ethanol fermentation of the same raw material is superior to the traditional ethanol fermentation. The reasons may be as follows:

In the manual operation of ethanol production, more contact with raw materials will result in greater loss of raw materials and the actual error is large.

Stock of different air. Yeast as facultative anaerobic unicellular fungi, stock in the fermentation tank air will provide good oxygen for yeast, yeast in it for aerobic organisms, yeast aerobic reproduction after using the remaining residual oxygen in the air, into the anaerobic environment, type of yeast fermentation through convert sugars into carbon dioxide and ethanol to obtain energy [17]. Therefore, it is necessary to have a moderate amount of air surplus. The air stock of the 10L glass fermentation tank used in the traditional laboratory for small-scale ethanol fermentation is limited, while the steel fermentation tank used in the production of ethanol by the pilot equipment is equipped with a vent hole, and the air stock is large.

Degree of fermentation with yeast in contact with the raw material have difference, the traditional laboratory small ethanol fermentation by way of $10 \mathrm{~L}$ fermentation tank fermentation glass belongs to static fermentation, yeast distribution uniformity is limited, lead to inadequate contact with raw materials, low utilization rate of raw materials. The test equipment for production of ethanol by fermentation tank of the upper rotating device, fermentation methods belong to the static fermentation, makes the yeast evenly dispersed in the raw material, fully contact with the raw material, the maximum use of raw materials, for anaerobic respiration.

Operating outside contact with the raw material is different, the traditional laboratory small ethanol fermentation, the raw material contact with the outside world more, could lead to more bacterial pollution. In the Fermentation system, yeast as the advantage bacterium group, too much miscellaneous bacterium, inhibits the yeast anaerobic respiration, directly affect the utilization rate of raw materials, severe cases can cause the failure of the experiment. The test equipment for production of ethanol, the less raw material contact with the outside world, greatly reduced the possibility of bacterial contamination, and test equipment for production of ethanol, in the saccharifying tank for high temperature and high pressure disinfection sterilization, it can reduce bacterial doping and guarantee the yeast that can make full use of raw materials, it is significantly reduced in the experiment the possibility of failure.

\section{Conclusions}

With the continuous development of modern biological technology and engineering technology, ethanol will continue to be innovative and improve production technology, raw materials and the kinds of biological species can be used in the production of ethanol will become increasingly diversified. In the past to food crops to corn as the main raw material to produce ethanol, the production cost is relatively high, and don't suit the basic national conditions of our country people much less. At present, in the process of producing ethanol with sugar raw materials and starch as raw materials at home and abroad, the cost of producing raw materials accounts for more than $50 \%$ of the total production cost. Therefore, one option to reduce the production cost of ethanol is to develop cheap raw materials resources and reasonable renewable energy [18]. Wood is rich in cellulose, which can also be used for the production of ethanol, but its structural composition is relatively complex, and it must be hydrolyzed and saccharized before it can be used by yeast to achieve the production of ethanol. However, the lignin contained in wood will hinder the hydrolysis of cellulose by cellulose. Therefore, before enzymatic hydrolysis of cellulose, the necessary pretreatment is needed to increase the contact between cellulase and cellulose [19]. Enzymatic hydrolysis with simple equipment, mild reaction conditions, high rate of raw materials for saccharification and by-products and less polluting the environment, it got more widely application. Additionally, there are many fungi (white-rot fungus, brown rot fungi and soft rot bacteria, etc.) have the ability to decompose lignin in the future, it also can be used in the pretreatment of lignocellulose materials [20]. As the price of oil rises, the demand for alcohol will also increase. At the same time, the development of fermented alcohol not only cassava raw 
materials, but also cassava residue, it is a by-product of a large number of flour mills with a relatively low cost. Therefore, cassava fermented alcohol should be feasible [21]. Except for fuel ethanol, it also can be used as a kind of chemical raw materials and intermediate products are widely used in pharmaceutical, chemical, food and military and other industries, such as used in the production demand of ethylene and polyethylene, polyvinyl chloride, ethyl acetate and other organic chemical products, the by-product of $\mathrm{CO}_{2}$ can be used in the production of new, safe, biodegradable plastics [22]. We can improve the rate of wine in order to make full use of biomass energy by adjusting the process parameters and optimization of technological process at the same time, the goal is achieve saving energy, economic and environmental protection. In this paper, the aim is to verify and explore the traditional experiment and the industrial experiment of different process parameters with the experiment. Based on the data and method, this study will be used to prepare for the next work, the results of the study for further research of ethanol fermentation process in the future, and it is of great significance to explore new technology.

\section{Acknowledgements}

This paper was supported by the Jointly Foundation of National Fund Project (51366015), Renewable Energy Research \& Development Collaborative Innovation Center in Southwest (05300205020516009), and Scientific Research Fund Project of Yunnan Provincial Department of Education (2018JS146).

\section{References}

[1] Ban Meiling, Zhou Shengmao, Wei Benhui, Lin Weidong, Li Baohui. The advantages, problems and countermeasures of guangxi energy cassava sustainable development [J]. Anhui Agricultural Sciences, 2007 (33): 10824-10827.

[2] Cai Yonghong. The chemical industry innovation of fuel ethanol process [J]. China Chemical Trade, 2013 (12): 370-370. DOI: $10.3969 /$ j. issn.1674-5167.2013.12.350.

[3] Dong Dandan, Zhao Daiqing, Liao Cuiping, Chen Xiansheng, Lin Lin. Technology improvement of cassava fuel ethanol production and analysis of energy consumption of whole life cycle [J]. Agricultural Engineering, 2008 (07): 160-164.

[4] Fei Lan. Study on optimal degradation conditions of enteromorpha biomass and ethanol production by fermentation [D]. Shanghai Ocean University, 2014.

[5] Xu Xiaojing. Study on the construction of high yield ethanol strain of recombinant saccharomyces cerevisiae and its clean fermentation technology [D]. Tianjin University, 2009.

[6] Chen Yuliang. A preliminary study on saccharification fermentation of ethanol from wheat straw [D]. Northwest Agriculture \& Forestry University, 2009.

[7] Wei Yingzhi, Huo Hanjun. The temperature of beer fermentation tank was controlled automatically by PLC [J]. Modern Electronics Technique, 2002 (12): 90-91.

[8] He Juanjuan. SRMBR ethanol continuous fermentation separation and membrane flow field simulation [D]. Sichuan University, 2006.

[9] Han Xiaolong. Study on improving alcohol production rate of cassava raw material [D]. Shandong Polytechnic University, 2007.

[10] Zhang Cheng, Yuan Hongzhi. The effect of temperature on the activity of ethanol dehydrogenase in fermentation process [J]. Shanxi science and technology, 2008 (04): 100+104.

[11] Yue Guojun, Wu Guoqing, Hao xiaoming. Current situation and prospect of fuel ethanol production technology in China [J] Progress in chemistry, 2007, 19 (7/8): 1085-1090.

[12] Liu Haijun, Li Lin, Bai Dianguo. Analysis on current situation and development prospect of fuel ethanol production technology in China [J]. Chemical Process Technology, 2012, 20 (5): 68-72.

[13] Yuan Jingwei, Cong Zhihui, Liu Hui, Liang Chunhui. Study on technical conditions of corn ethanol biomass fermentation [J]. Liquor-Making Science \& Technology, 2017 (12): 88-92.

[14] Chinese academy of agricultural sciences. AMYA4 and its genes and applications: China, CN201010219720.9 [P].2010-11-17.

[15] Xu Huijuan, Wang Shifeng, Long Minnan. Research progress in fuel alcohol production $[\mathrm{J}]$. Journal of xiamen university (natural science edition), 2006 (S1): 37-42.

[16] Wang Huijun. The application and development countermeasure of cassava [A]. Selected excellent papers of yunnan provincial crop association from 2004 to 2006 [C]: 2006: 4.

[17] Deng Likang, Wu Guoqing, Lin Hailong. Cassava fuel ethanol plant and key technologies [C]// Proceedings of the 6th academic conference on petroleum refining of China petroleum institute. 2010: 725 .

[18] Ljiljana, Mojović, Dušanka, Pejin, Marica, Rakin, etc. Investigations of the possibilities of stillage utilization from the bioethanol production on corn [J]. Journal on Processing and Energy in Agriculture, 2010, 14 (1): 54-57.

[19] Tristan R, Robert C. A review of cellulosic biofuel commercial scale projects in the United States [J]. Biofuels Bioproducts and Biorefining, 2013, 7 (3): 235-245.

[20] Zhao Peng, Huang Xia. Research progress on lactic acid production by fermentation with renewable resources and organic waste $[\mathrm{J}]$. Food and Fermentation Industries, 2001 (04): $60-65$.

[21] Gao Shouqing. The development of biomass fuel ethanol and the problems to be solved [J]. Food and Fermentation Industries, 1991 (01): 54-60.

[22] Yin Fang, Li Yingjuan, Zhang Wudi, Huang Wenrong, Hu Xieke, Liu Shiqing, Lei Yu, Tian Guangliang, Yang Bin. Development status and countermeasures of fuel ethanol industry in yunnan province [J]. Chemical Industry and Engineering Progress, 2015, 34 (S1): 55-59. 